\title{
The Propagation of Antisymmetric Lamb Wave in the Hollow Cylinder
}

\author{
Yu. V. Myshkin ${ }^{1}$, O. V. Muravieva ${ }^{1,2}$, S. Yu. Voronchikhin ${ }^{3}$, A. A. Pon'kina ${ }^{1}$, \\ S. A. Korolev ${ }^{1}$ \\ ${ }^{1}$ Department of Instruments and Techniques of Measurements, Testing, Diagnostics, \\ Kalashnikov Izhevsk State Technical University, Izhevsk, Russian Federation \\ ${ }^{2}$ Udmurt Federal Research Center of Ural Branch of the Russian Academy of Sciences, \\ Izhevsk, Russian Federation \\ ${ }^{3}$ IntroScan Technology JSC, Chaykovsky, Perm Krai, Russian Federation \\ E-mail: mubm@yandex.ru
}

Received: August 16, 2020

\begin{abstract}
The article presents research on the propagation of an antisymmetric Lamb wave mode in a hollow steel cylinder with an outer diameter of $1020 \mathrm{~mm}$ and a wall thickness of $16 \mathrm{~mm}$ at frequencies of 50 and $120 \mathrm{kHz}$. Dispersion curves for a pipe and a plate are given, examples of which show their similarity in the frequency range from $5 \mathrm{kHz}$ and the presence of higher-order modes. Experimental studies were carried out using piezoelectric transducers with dry point contact on a spiral welded pipe. The research results showed the combined effect of the geometric anisotropy and anisotropy of the pipe material properties on the propagation velocity of the antisymmetric Lamb wave mode. The maximum difference in velocity depending on the angle of deviation of the wave propagation trajectory (deviation angle) was 35 and $55 \mathrm{~m} / \mathrm{s}$ at a frequency of 50 and $120 \mathrm{kHz}$, respectively. The effect of the pipe wall thickness on the character of the dependence of the velocity on the deviation angle in the presence of dispersion was established, which amounted to $20 \mathrm{~m} / \mathrm{s} \mathrm{per} 1 \mathrm{~mm}$ of wall thickness for a given pipe geometry. A qualitative description of the formation of the shape of the dependence of the wave velocity on the deviation angle, which has a minimum at 30 degrees and a maximum at 90 degrees, is presented.
\end{abstract}

Keywords: Lamb wave, hollow cylinder, wave velocity, experimental study, dry point contact, guided wave testing, geometric anisotropy, spiral welded pipe.

\section{INTRODUCTION}

Modern methods of non-destructive testing make it possible to simultaneously detect defects, carry out thickness measurement and evaluate the structure of the material (structural health monitoring) [1-14]. One of these methods is acoustic guided wave testing, based on the use of guided waves, in particular, horizontally polarized shear wave, symmetric and antisymmetric Lamb wave modes. The choice of the type of wave during acoustic guided wave testing depends on its features: the presence of velocity dispersion; sensitivity to orientation, shapes and types of defects; applicability to the geometry of the testing object; properties of the material of the testing object, etc. [10-14]

(C) Yu. V. Myshkin, O. V. Muravieva, S. Yu. Voronchikhin, A. A. Pon'kina, S. A. Korolev, 2020 
The antisymmetric Lamb wave mode has not been widely used in the detection of defects due to the high dispersion of the velocity. However, this type of wave, along with resonance methods, is convenient to use for determining the dimensions of the thickness of plates and pipe walls. Using several emitters and receivers and algorithms for synthetic or active focusing, it is also used to determine the coordinates of local thinning of the walls of the pipe or plates [15-20]. Due to the high dispersion of the velocity of Lamb waves, these techniques allow them to be used in monitoring the structure and properties of a material [21-24], acoustic tomography [25-29], monitoring layered structures made of composite materials [20, 3033], study of attenuation on discontinuities in plates [31, 34-36].

As a rule, when studying the processes of propagation of Lamb waves and evaluating research results, the following methods are used: the semi-analytical method of finite elements [37], the method of finite elements [18, 31, 35, 38, 39], Legendre spectral element method [22], dispersion ultrasound vibrometry method [24], spectral analysis [32], analytical methods [40,41], experimental experiments [23, 39]. To excite Lamb waves, the following methods and transducers are used: piezoelectric transducers [16, 17, 21, 42], electromagnetic-acoustic transducers [27, 43, 44], laser method [23, 45, 46], air-coupled transducers [39, 47, 48]. In research and practical use, the antisymmetric Lamb wave mode often becomes an interfering factor in the interpretation of testing results $[19,43]$.

When testing pipe wall thickness using an antisymmetric Lamb wave mode, the analysis of the results becomes more difficult, since all guided wave types are influenced by both the anisotropy of the pipe material properties and the geometric anisotropy. Studies on the influence of geometric anisotropy on the propagation velocity of the symmetric Lamb wave mode and the horizontally polarized shear wave are presented in [49-51]. Geometric anisotropy can change the wave velocity depending on the pipe geometry within the range up to $300 \mathrm{~m} / \mathrm{s}$ from the calculated theoretical value.

The article presents the results of studies on the influence of geometric anisotropy and the anisotropy of the pipe material properties on the propagation velocity of the antisymmetric Lamb wave mode in a spiral welded pipe with diameter of $1020 \mathrm{~mm}$ and a wall thickness of $16 \mathrm{~mm}$.

\section{DISPERSION CURVES}

Dispersion curves of phase and group velocities calculated in the Elastic Waveguide Tracer program were obtained for the pipe of the specified geometry (figure 1). For comparison, dispersion curves for a $16 \mathrm{~mm}$ thick plate are also shown (figure 2). The parameters for calculating the curves are given in the table 1 . Since the experimental studies used transducers operating at a frequency of 50 and $120 \mathrm{kHz}$, then the velocities of all types of waves were calculated for them, which are presented in the table 2 and table 3 respectively. From the presented dispersion curves (figure 1 and figure 2) and the results of calculating the velocity (table 2 and table 3), it can be seen that the differences in the group and phase velocities for the pipe and plate are insignificant in the frequency range from $5 \mathrm{kHz}$ and more. The main difference lies in the presence of higher-order modes in pipes at high frequencies, propagating at the same velocity as waves in the plate, and having distinctive diagrams of displacement components along the pipe wall thickness.

It can be seen from the velocities calculated from the dispersion curves that the velocity of the antisymmetric Lamb wave mode does not differ much from the velocity of the horizontally polarized shear wave. In particular, at $120 \mathrm{kHz}$, the velocities are practically the same. However, two types of waves can be distinguished by the direction of particle oscillations in the displacement diagram, since the horizontal component of displacements prevails in the 
horizontally polarized shear wave, and in the antisymmetric Lamb wave mode, the normal component of displacements prevails.
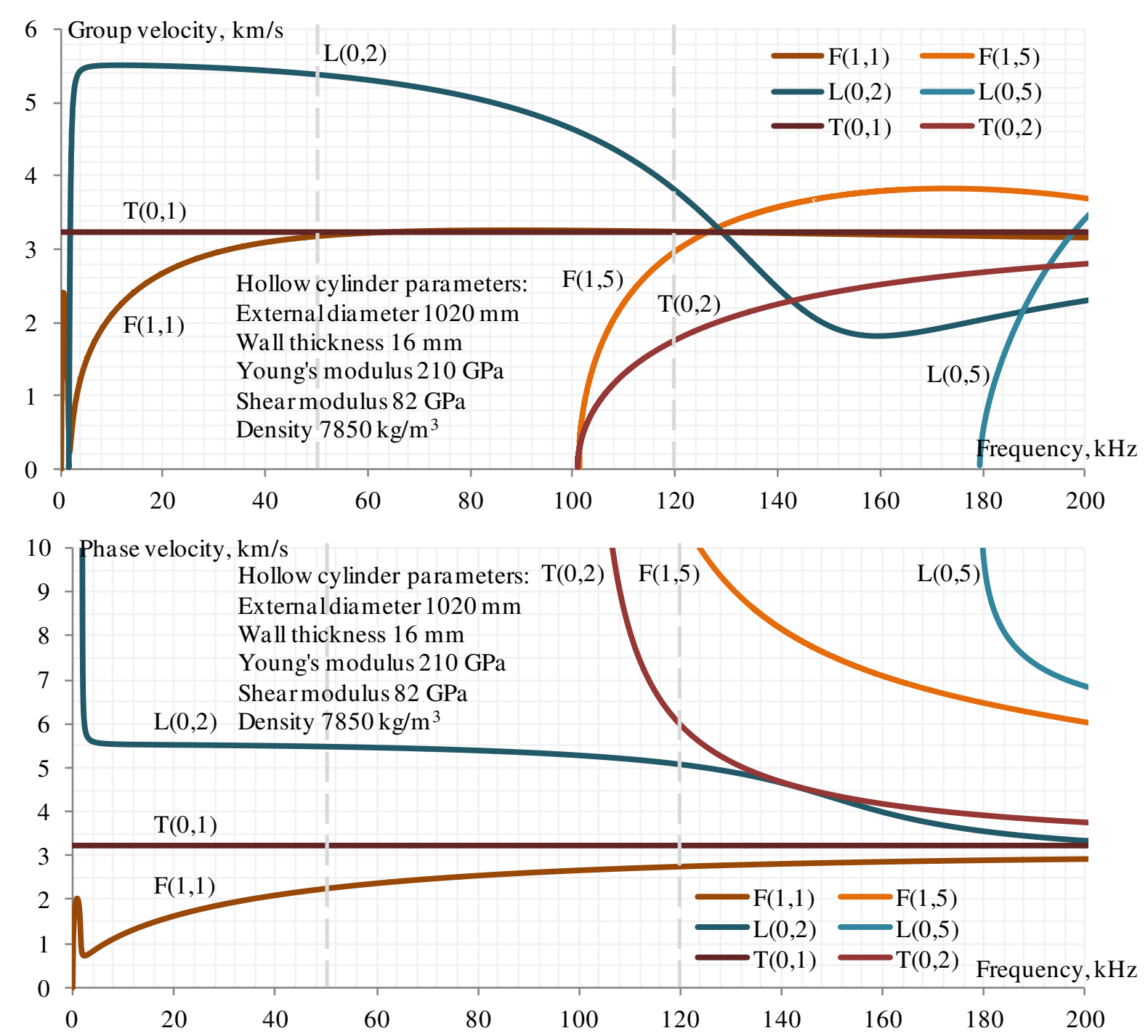

Figure 1. Dispersion curves of group and phase velocities in a steel hollow cylinder (b):

$\mathrm{L}$ - longitudinal wave, $\mathrm{F}$ - flexural wave, $\mathrm{T}$ - torsional wave

Table 1. Geometric and material properties

\begin{tabular}{c|c|c|c|c|c}
\hline Parameter & Value & Dimension & Parameter & Value & Dimension \\
\hline External radius & 510 & $\mathrm{~mm}$ & Shear modulus, $G$ & 82 & $\mathrm{GPa}$ \\
Wall thickness & 16 & $\mathrm{~mm}$ & Poisson's ratio, $\eta$ & 0.28 & - \\
Internal radius & 494 & $\mathrm{~mm}$ & Shear wave velocity, $C$ & 3243 & $\mathrm{~m} / \mathrm{s}$ \\
Young's modulus, $E$ & 210 & $\mathrm{GPa}$ & Density, $\rho$ & 7850 & $\mathrm{~kg} / \mathrm{m}^{3}$ \\
\hline
\end{tabular}

Table 2. Group velocities at the frequency of $50 \mathrm{kHz}$

\begin{tabular}{c|c|c|c}
\hline Mode in plate & Group velocity $(\mathbf{m} / \mathbf{s})$ & Mode in pipe & Group velocity $(\mathbf{m} / \mathbf{s})$ \\
\hline A0 & 3181 & $\mathrm{~F}(1,1)$ & 3179 \\
S0 & 5391 & $\mathrm{~L}(0,2)$ & 5391 \\
SH0 & 3242 & $\mathrm{~T}(0,1)$ & 3242 \\
\hline
\end{tabular}


Yu. V. Myshkin, O. V. Muravieva, S. Yu. Voronchikhin, A. A. Pon'kina, S. A. Korolev "The propagation of antisymmetric Lamb wave in the hollow cylinder"

\begin{tabular}{c|c|c|c}
\hline \multicolumn{4}{c}{ Table 3. Group velocities at the frequency of $120 \mathrm{kHz}$} \\
\hline Mode in plate & Group velocity $(\mathbf{m} / \mathbf{s})$ & Mode in pipe & Group velocity $(\mathbf{m} / \mathbf{s})$ \\
\hline A0, A1 & 3242,2976 & $\mathrm{~F}(1,1), \mathrm{F}(1,5)$ & 3242,2979 \\
S0 & 3809 & $\mathrm{~L}(0,2)$ & 3810 \\
SH0, SH1 & 3242,1746 & $\mathrm{~T}(0,1), \mathrm{T}(0,2)$ & 3242,1746 \\
\hline
\end{tabular}

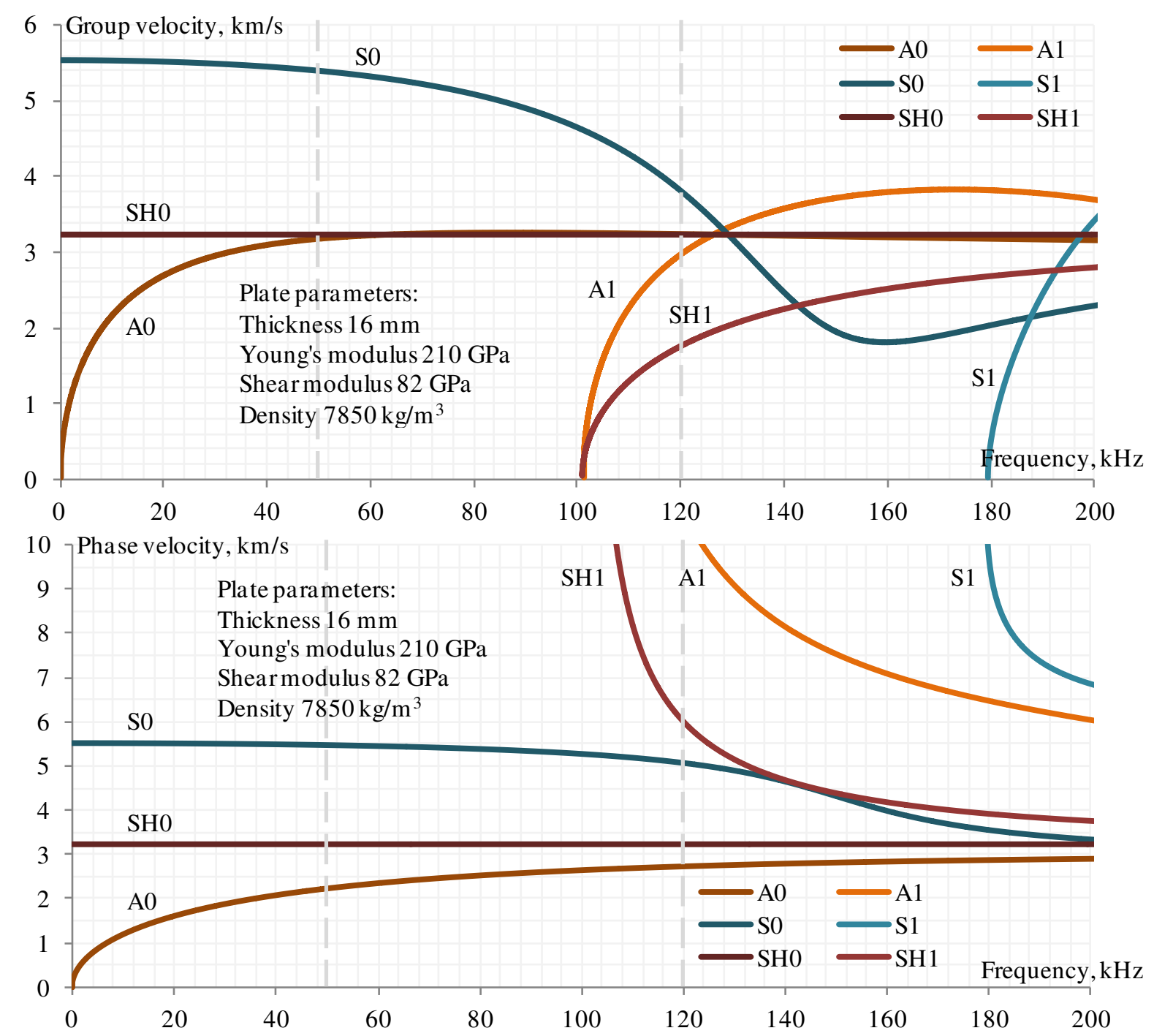

Figure 2. Dispersion curves of group and phase velocities in a steel plate: $\mathrm{S}$ - symmetrical mode of Lamb wave, A - antisymmetrical mode of Lamb wave, SH - horizontally polarized shear wave

To separate wave types in experimental studies, specialized designs and orientations of transducers were used, which made it possible to create tangential or normal displacements on the surface of the testing object.

\section{EXPERIMENTAL SETUP}

The experimental setup included a stand consisting of a system of pipelines of various diameters, two piezoelectric transducers with dry point contact, and a DIO-1000LF flaw detector (figure 3). A pipeline with a diameter of $1020 \mathrm{~mm}$ was marked on the outside with 
a specialized template in such a way that the points for installing the receiving transducer were located at a distance of $1 \mathrm{~m}$ from the point of installing the emitter with a step of $1 \mathrm{de}$ gree. The marking and measurements were carried out in one quadrant in the range of angles from 0 to 90 degrees, while the direction along the axis along the pipe generatrix was taken as 0 degrees. As already noted, for the excitation and reception of the antisymmetric Lamb wave mode, the normal component of the displacements was used, created and recorded by piezoelectric transducers with dry point contact.
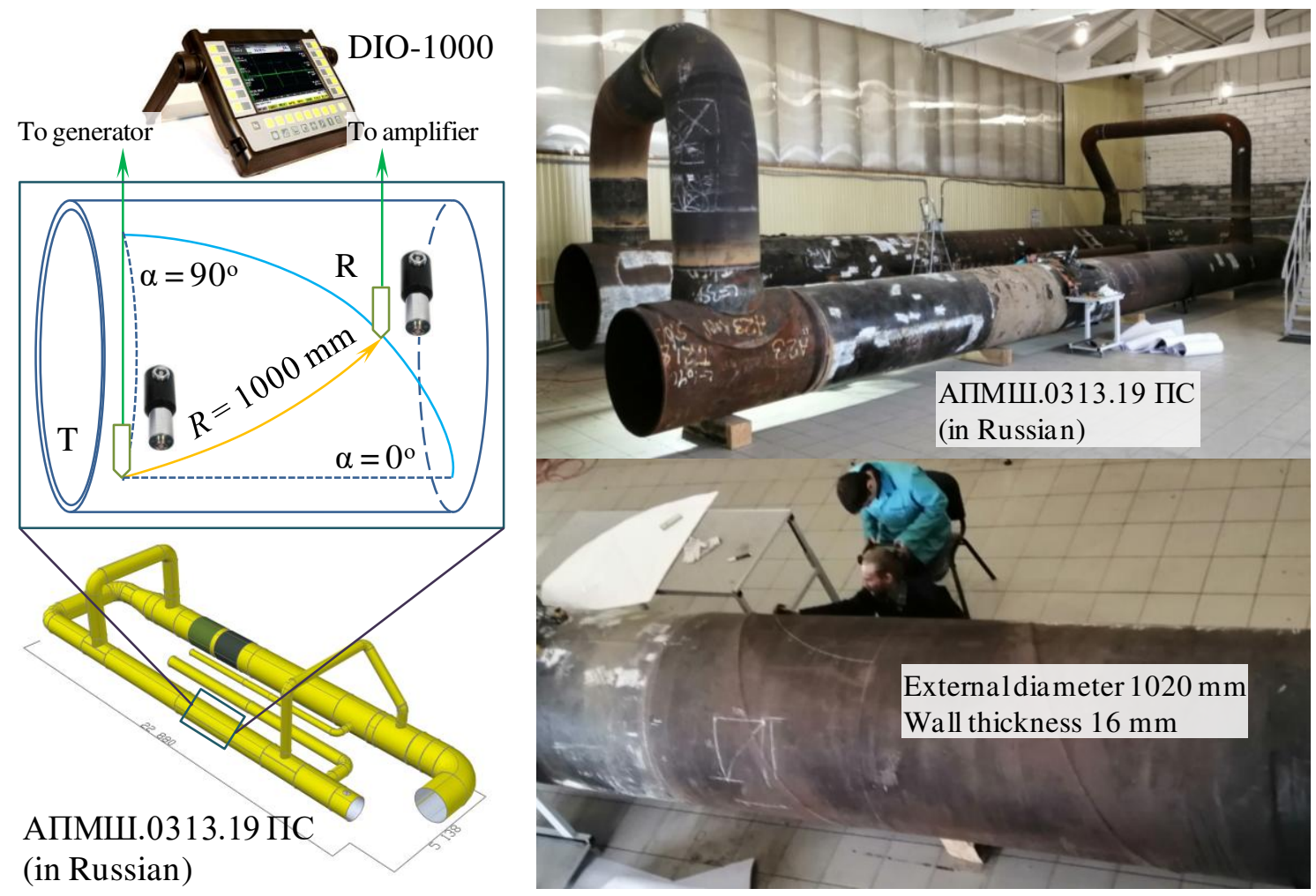

Figure 3. A scheme and photo of the experimental setup: $\alpha$-deviation angle - angle of deviation of the path of wave propagation from pipe generatrix, $\mathrm{T}-$ transmitter, $\mathrm{R}-$ receiver

As a result of measurement, the figure 4 shows an echogram at the point of reception of oscillations of a signal transmitted once from the transmitter to the receiver. To increase the accuracy of calculating the wave velocity, the range of the recorded signal was limited by the window including the beginning $(310 \mu \mathrm{s})$ and end $(400 \mu \mathrm{s})$ of the echo pulse of the antisymmetric Lamb wave mode, while the signal sampling rate was $200 \mathrm{MHz}$.

For the time of arrival of the pulse (time of flight), the average value of the time, the observed maxima and minima in the limited window of the recorded signal was taken, which made it possible to detach from the influence of acoustic and electrical noises. Taking into account the delay in the transducer and the time shift, calculated by the correlation method and amounting to 34 and $51 \mu \mathrm{s}$ at a frequency of 50 and $120 \mathrm{kHz}$, respectively, the wave propagation velocity was calculated for a known fixed base of $1000 \mathrm{~mm}$.

\section{RESULTS AND DISCUSSION}

The final result was the dependence of the propagation velocity of the antisymmetric Lamb wave mode on the angle of deviation of the path of wave propagation from pipe 
generatrix (deviation angle), i.e. 0 degrees - direction along the pipe, along the generatrix, 90 degrees - circumferential direction of the pipe, along the envelope (figure 5).
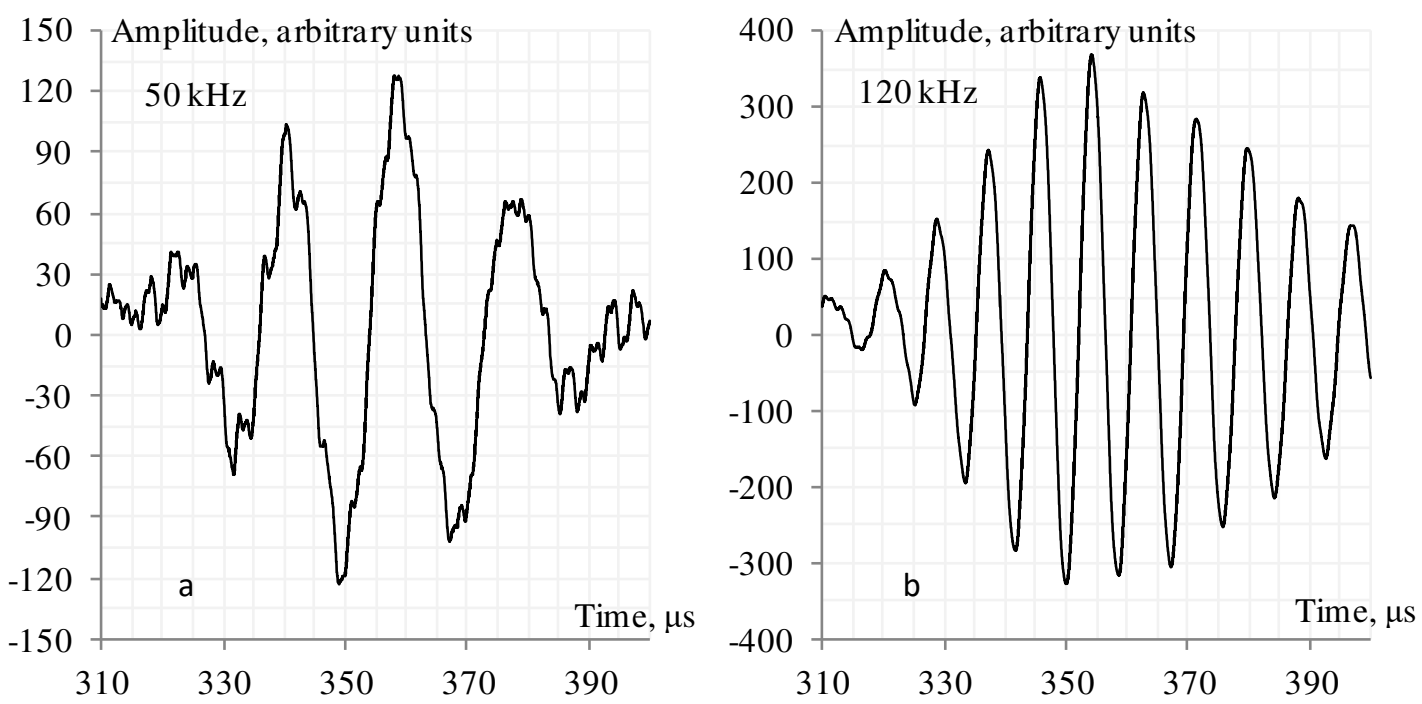

Figure 4. The received signal recorded by flaw detector at frequency of $50 \mathrm{kHz}$ (a) and $120 \mathrm{kHz}$ (b)
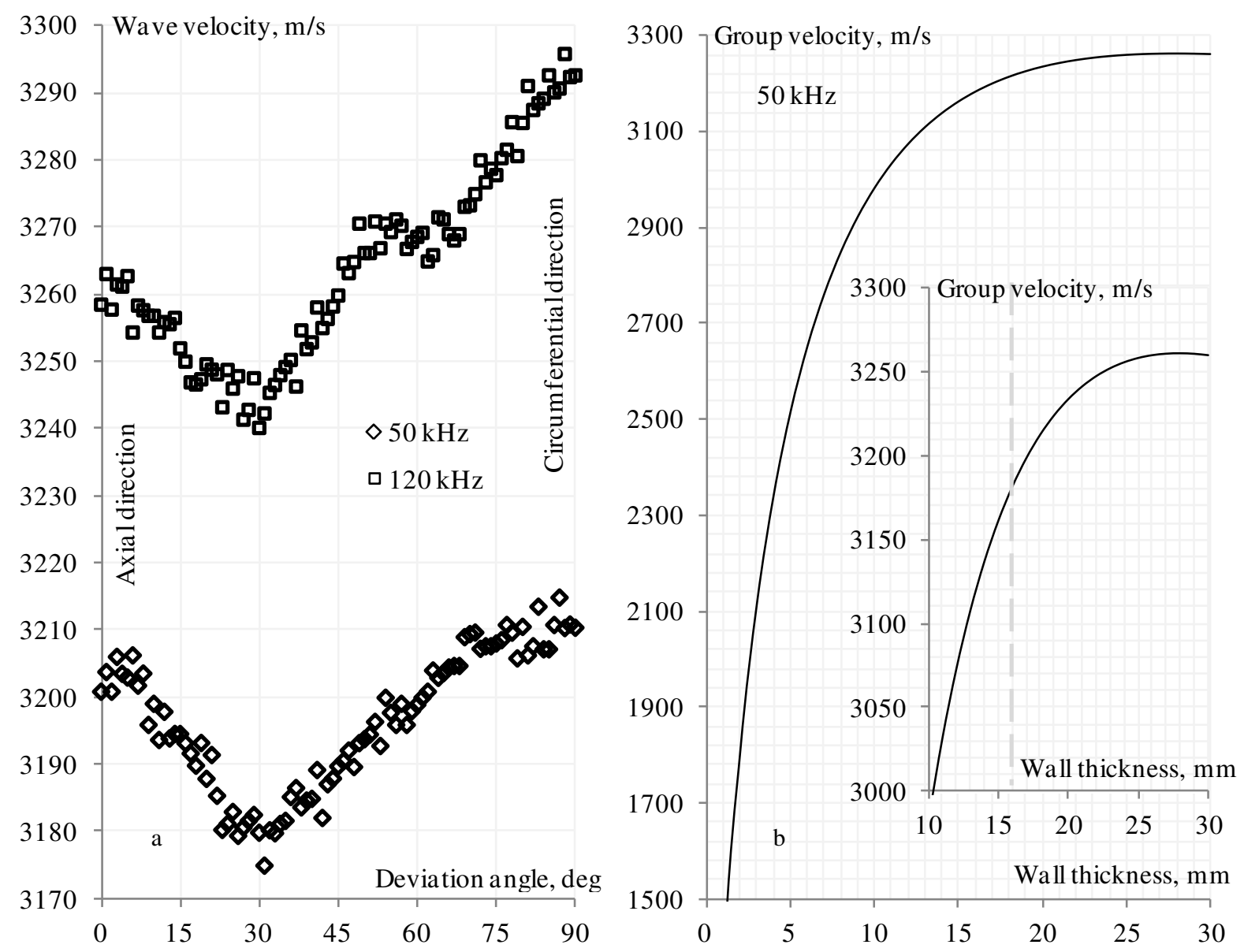

Figure 5. Dependence of antisymmetric Lamb wave mode on direction of the propagation in the hollow steel cylinder (a) and dependence of group velocity of antisymmetric Lamb wave mode on wall thickness in a steel plate at frequency of $50 \mathrm{kHz}$ (b): deviation angle - angle of deviation of the path of wave propagation from pipe generatrix 
The obtained dependence (figure 5a) shows two extrema: a maximum at an angle of 90 degrees and a minimum at an angle of 30 degrees. These extrema are explained by the simultaneous influence of the anisotropy of the pipe material properties and the geometric anisotropy (figure 6). The appearance of the maximum (figure 6b) is primarily explained by the presence of geometric anisotropy, as described in $[49,51]$, and its displacement relative to the pipe envelope (90 degrees) is associated with the anisotropy of the material properties (figure 6c). This shift will be the greater, the greater the anisotropy of the material properties (figure 6a). Also, the maximum and minimum are additionally shifted relative to the directions along the envelope (90 degrees) and along generatrix ( 0 degrees) of the pipe, respectively, due to the orientation of the sheet with pronounced anisotropy properties in the spiral welded pipe (figure $6 \mathrm{~d})$.
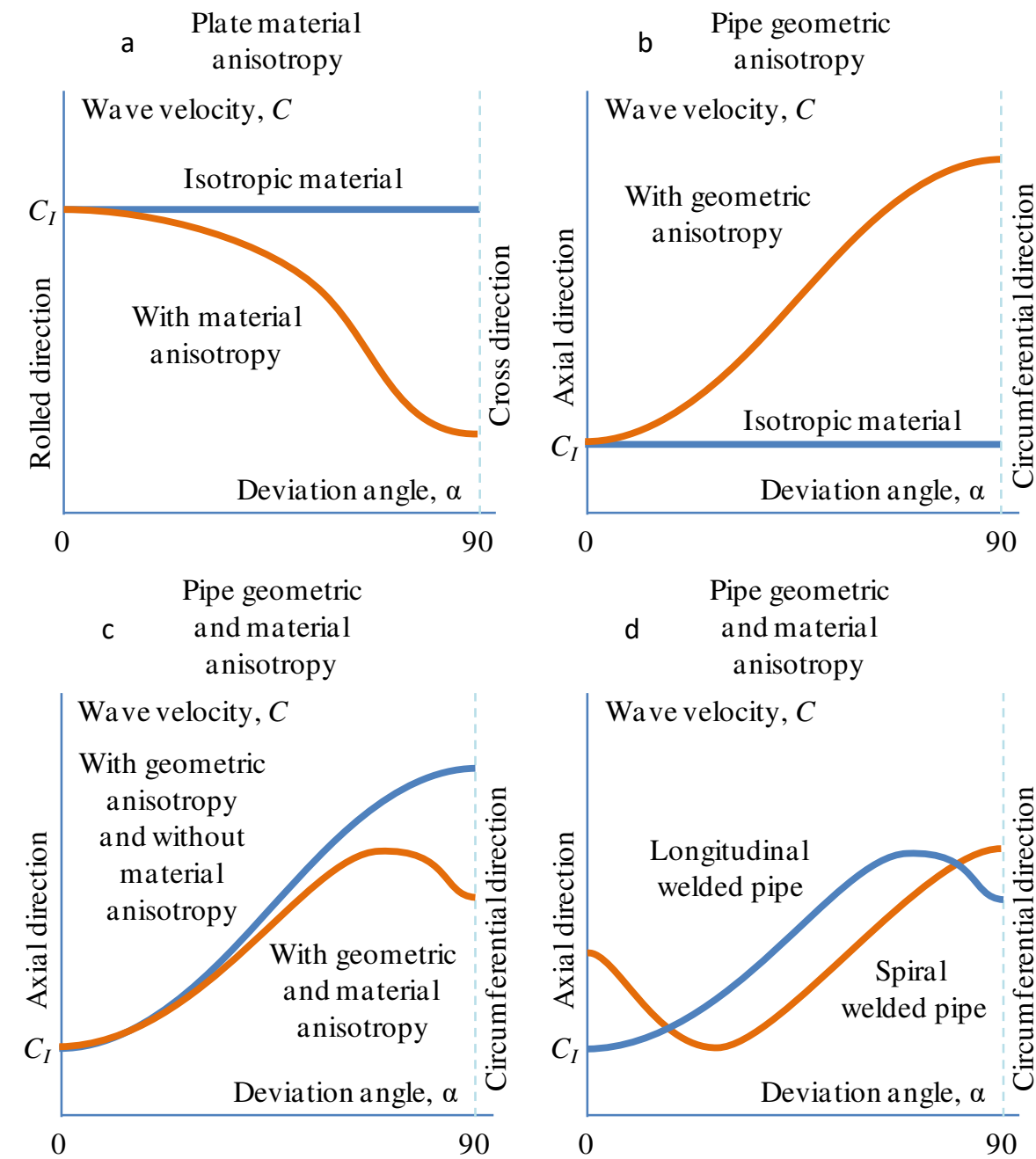

Figure 6. Schematic explanation of the formation of the shape of the dependence of the wave velocity on the deviation angle (degrees) in a spiral welded pipe: (a) influence of anisotropy of material properties, (b) influence of geometric anisotropy, (c) influence of anisotropy of material properties and geometric anisotropy, (d) influence of anisotropy of material properties and geometric anisotropy in spiral welded pipe, $C_{I}$ - theoretical value of the wave velocity in isotropic material

Since the dispersion of the velocity of the antisymmetric Lamb wave mode is more pronounced at low frequencies, the qualitative dependences of the velocity at frequencies of 50 and $120 \mathrm{kHz}$ have different forms. Velocities values change within range from $3240 \mathrm{~m} / \mathrm{s}$ to 
$3295 \mathrm{~m} / \mathrm{s}$ with $55 \mathrm{~m} / \mathrm{s}$ range span at $120 \mathrm{kHz}$ and $3180 \mathrm{~m} / \mathrm{s}$ to $3215 \mathrm{~m} / \mathrm{s}$ with $35 \mathrm{~m} / \mathrm{s}$ range span at $50 \mathrm{kHz}$. In this case, at a frequency of $120 \mathrm{kHz}$, a "step" is observed in the range of angles from 50 to 65 degrees, caused by the presence of modes of a higher order.

Since geometric anisotropy has the same effect on the wave velocity at any frequency $[50,51]$, changes in the velocity range are associated with the anisotropy of the material properties and, to the greatest extent, with the velocity dispersion, caused by the influence of the pipe geometry. In this case, the more pronounced the velocity dispersion, the greater the influence on the change in the wave velocity is exerted by the pipe geometry. Thus, at a frequency of $50 \mathrm{kHz}$, when the pipe wall thickness changes from $16 \mathrm{~mm}$ to $1 \mathrm{~mm}$, the velocity of the antisymmetric Lamb wave mode will change by $20 \mathrm{~m} / \mathrm{s}$, and at a wall thickness of $28 \mathrm{~mm}$, the velocity will not change, i.e. the wave will not be sensitive to changes in the wall thickness with the given testing parameters.

\section{CONCLUSIONS}

Thus, based on the results of studies of the propagation of the antisymmetric Lamb wave mode in a hollow cylinder, the following conclusions can be drawn:

- qualitatively, the dependence of the velocity of the antisymmetric Lamb wave mode on the angle of deviation of the path of wave propagation from pipe generatrix is similar to the dependence of the horizontally polarized shear;

- to separate the types of waves during their excitation and reception, it is necessary to take into account the diagram of displacements in the wave at the given frequency;

- the limits of changing the velocity range at frequencies of $50 \mathrm{kHz}$ and $120 \mathrm{kHz}$ for a pipe with a diameter of $1020 \mathrm{~mm}$ and a wall thickness of $16 \mathrm{~mm}$ are $35 \mathrm{~m} / \mathrm{s}$ and $55 \mathrm{~m} / \mathrm{s}$, respectively;

- the more pronounced the velocity dispersion, the more sensitive the wave to the pipe geometry;

- anisotropy of material properties is additionally superimposed on geometric anisotropy, which is expressed in displacements of extrema in the dependences of velocity on the angle of deviation of the path of wave propagation from pipe generatrix.

The research results can be used to improve the methods of guided wave testing, develop piezoelectric transducers with dry point contact and testing systems for flaw detection, thickness measurement and structural health monitoring of pipelines and their products.

\section{ACKNOWLEDGEMENTS}

This work was supported by the Russian Science Foundation (Project No. 18-79-10122).

\section{REFERENCES}

1. Buldakova, I. V., Volkova, L. V., \& Muravyev, V. V. (2020). Stress distribution in pipe samples of gas pipelines with welded joints. Intellektual'nye sistemy v proizvodstve [Intelligent Systems in Manufacturing], 18(1), 4-8. doi: 10.22213/2410-9304-2020-1-4-8. (in Russian).

2. Murav'ev, V. V., Yakimov, A. V., Volkova, L. V., \& Platunov, A. V. (2019). Investigation of biaxial stress state in R65 rails by acoustoelasticity method. Intellektual'nye sistemy $v$ proizvodstve [Intelligent Systems in Manufacturing], 17(1), 19-25. doi: 10.22213/2410-9304-2019-1-19-25. (in Russian). 
3. Budrin, A. Y. (2020). The influence of heat treatment on the propagation velocity of shear waves in steel bars. Intellektual'nye sistemy v proizvodstve [Intelligent Systems in Manufacturing], 17(4), 12-17. doi: 10.22213/2410-9304-2019-4-12-17. (in Russian).

4. Ida, N., \& Meyendorf, N. (Eds.). (2019). Handbook of advanced non-destructive evaluation. Cham, Switzerland : Springer. ISBN 978-3-319-26553-7. doi: 10.1007/978-3-31930050-4.

5. Uglov, A. L., Hlybov, A. A., Bychkov, A. L., \& Kuvshinov, M. O. (2019). About nondestructive control of residual stresses in axisymmetric parts made of steel 03Ni17Co10W10MoTi. Bulletin of Kalashnikov ISTU, 22(4), 3-9. doi: 10.22213/24131172-2019-4-3-9. (in Russian).

6. Volkova, L. V., \& Platunov, A. V. (2019). Rail base point inspection using the mirror through transmission testing technique on multiple reflections. Bulletin of Kalashnikov ISTU, 22(4), 38-45. doi: 10.22213/2413-1172-2019-4-38-45. (in Russian).

7. Milovzorov, G. V., Ilyin, A. P., \& Red'kina, T. A. (2019). Methods for diagnosis of downhole pumping equipment condition based on dynamometry. Bulletin of Kalashnikov ISTU, 22(4), 64-72. doi: 10.22213/2413-1172-2019-4-64-72. (in Russian).

8. Uglov, A. L., Khlybov, A. A., Kolesnikov, M. V., Bystrukova, T. V., \& Bychkov, A. L. (2019). On ultrasonic control of the thickness of plasma surfacing of copper-nickel alloy on a steel cylindrical surface. Bulletin of Kalashnikov ISTU, 22(3), 3-10. doi: 10.22213/2413-1172-2019-3-3-10. (in Russian).

9. Syas'ko, V. A., Golubev, S. S., \& Ivkin, A. E. (2019). Experience of developing instruments for measuring firearm functional coating thickness. Bulletin of Kalashnikov ISTU, 22(3), 11-18. doi: 10.22213/2413-1172-2019-3-11-18. (in Russian).

10. Zlobin, D. V., \& Muravieva, O. V. (2012). Development features of electromagnetic acoustic defectoscopy equipment for bar iron using rod waves. Bulletin of Kalashnikov ISTU, (4), 099-104. ISSN 2413-1172. (in Russian).

11. Strizhak, V. A., Hasanov, R. R., \& Pryakhin, A. V. (2018). Features of excitation of an electromagnetic acoustic transducer under a waveguide method of testing. Bulletin of Kalashnikov ISTU, 21(2), 159-166. doi: 10.22213/2413-1172-2018-2-159-166. (in Russian).

12. Muravyova, O. V., \& Murashov, S. A. (2011). Use of torsional waves for detection of operational defects in pump rods and tubing. Bulletin of Kalashnikov ISTU, (2), 149-154. ISSN 2413-1172. (in Russian).

13. Strizhak, V. A., Pryakhin, A. V., Khasanov, R. R., \& Mkrtchyan, S. S. (2019). Flaw detection of composite rebar by acoustic wave guided technique. Bulletin of Kalashnikov ISTU, 22(1), 78-88. doi: 10.22213/2413-1172-2019-1-78-88. (in Russian).

14. Strizhak, V. A., Hasanov, R. R., \& Pryakhin, A. V. (2018). Features of excitation of an electromagnetic acoustic transducer under a waveguide method of testing. Bulletin of Kalashnikov ISTU, 21(2), 159-166. doi: 10.22213/2413-1172-2018-2-159-166. (in Russian).

15. Jenot, F., Ouaftouh, M., Duquennoy, M., \& Ourak, M. (2001). Corrosion thickness gauging in plates using Lamb wave group velocity measurements. Measurement Science and Technology, 12(8), 1287-1293. doi: 10.1088/0957-0233/12/8/341. 
16. Lowe, M. J. S., Cawley, P., Kao, J. Y., \& Diligent, O. (2000, May). Prediction and measurement of the reflection of the fundamental anti-symmetric Lamb wave from cracks and notches. AIP Conference Proceedings, 509(1), 193-200. doi: 10.1063/1.1306051.

17. Lowe, M. J., Cawley, P., Kao, J. Y., \& Diligent, O. (2002). The low frequency reflection characteristics of the fundamental antisymmetric Lamb wave a 0 from a rectangular notch in a plate. The Journal of the Acoustical Society of America, 112(6), 2612-2622. doi: 10.1121/1.1512702.

18. Lu, Y., Ye, L., Su, Z., \& Yang, C. (2008). Quantitative assessment of through-thickness crack size based on Lamb wave scattering in aluminium plates. NDT \& E International, 41(1), 59-68. doi: 10.1016/j.ndteint.2007.07.003.

19. Park, M. H., Kim, I. S., \& Yoon, Y. K. (1996). Ultrasonic inspection of long steel pipes using Lamb waves. NDT \& E International, 29(1), 13-20. doi: 10.1016/09638695(95)00030-5.

20. Ramadas, C., Janardhan Padiyar, M., Balasubramaniam, K., Joshi, M., \& Krishnamurthy, C. V. (2010). Delamination size detection using time of flight of anti-symmetric $\left(\mathrm{A}_{\mathrm{o}}\right)$ and mode converted $\mathrm{A}_{\mathrm{o}}$ mode of guided Lamb waves. Journal of Intelligent Material Systems and Structures, 21(8), 817-825. doi: 10.1177/1045389X10367836.

21. Giurgiutiu, V. (2005). Tuned Lamb wave excitation and detection with piezoelectric wafer active sensors for structural health monitoring. Journal of Intelligent Material Systems and Structures, 16(4), 291-305. doi: 10.1177/1045389X05050106.

22. Azizi, N., Saadatpour, M. M., \& Mahzoon, M. (2019). Analyzing first symmetric and antisymmetric Lamb wave modes in functionally graded thick plates by using spectral plate elements. International Journal of Mechanical Sciences, 150, 484-494. doi: $10.1016 /$

j.ijmecsci.2018.10.030.

23. Lasn, K., Klauson, A., Chati, F., \& Décultot, D. (2011). Experimental determination of elastic constants of an orthotropic composite plate by using lamb waves. Mechanics of Composite Materials, 47(4), 435. doi: 10.1007/s11029-011-9221-y.

24. Nenadic, I. Z., Urban, M. W., Mitchell, S. A., \& Greenleaf, J. F. (2011). Lamb wave dispersion ultrasound vibrometry (LDUV) method for quantifying mechanical properties of viscoelastic solids. Physics in Medicine \& Biology, 56(7), 2245-2264. doi: 10.1088/00319155/56/7/021.

25. Leonard, K. R., Malyarenko, E. V., \& Hinders, M. K. (2002). Ultrasonic Lamb wave tomography. Inverse problems, 18(6), 1795-1808. doi: 10.1088/0266-5611/18/6/322.

26. Zhao, X., Royer, R. L., Owens, S. E., \& Rose, J. L. (2011). Ultrasonic Lamb wave tomography in structural health monitoring. Smart Materials and Structures, 20(10), 105002. doi: 10.1088/0964-1726/20/10/105002.

27. Ho, K. S., Billson, D. R., \& Hutchins, D. A. (2007). Ultrasonic Lamb wave tomography using scanned EMATs and wavelet processing. Nondestructive Testing and Evaluation, 22(1), 19-34. doi: 10.1080/10589750701327890.

28. Pei, J., Yousuf, M. I., Degertekin, F. L., Honein, B. V., \& Khuri-Yakub, B. T. (1996). Lamb wave tomography and its application in pipe erosion/corrosion monitoring. Journal of Research in Nondestructive Evaluation, 8(4), 189-197. doi: 10.1007/BF02433949. 
29. Leonard, K. R., \& Hinders, M. K. (2003). Guided wave helical ultrasonic tomography of pipes. The Journal of the Acoustical Society of America, 114(2), 767-774. doi: 10.1121/1.1593068.

30. Wang, L., \& Yuan, F. G. (2007). Group velocity and characteristic wave curves of Lamb waves in composites: Modeling and experiments. Composites Science and Technology, 67(7-8), 1370-1384. doi: 10.1016/j.compscitech.2006.09.023.

31. Veidt, M., \& Ng, C. T. (2011). Influence of stacking sequence on scattering characteristics of the fundamental anti-symmetric Lamb wave at through holes in composite laminates. The Journal of the Acoustical Society of America, 129(3), 1280-1287. doi: 10.1121/1.3533742.

32. Kim, Y. H., Kim, D. H., Han, J. H., \& Kim, C. G. (2007). Damage assessment in layered composites using spectral analysis and Lamb wave. Composites Part B: Engineering, 38(7-8), 800-809. doi: 10.1016/j.compositesb.2006.12.010.

33. Bingham, J., \& Hinders, M. (2009). Lamb wave detection of delaminations in large diameter pipe coatings. The Open Acoustics Journal, 2(1), 75-86. doi: 10.2174/ 1874837600902010075.

34. Soleimanpour, R., \& Ng, C. T. (2016). Scattering of the fundamental anti-symmetric Lamb wave at through-thickness notches in isotropic plates. Journal of Civil Structural Health Monitoring, 6(3), 447-459. doi: 10.1007/s13349-016-0166-7.

35. Ng, Ching-Tai. (2015). On accuracy of analytical modeling of Lamb wave scattering at delaminations in multilayered isotropic plates. International Journal of Structural Stability and Dynamics, 15(8), 1540010. doi: 10.1142/S0219455415400106.

36. Chen, J., Su, Z., \& Cheng, L. (2009). Identification of corrosion damage in submerged structures using fundamental anti-symmetric Lamb waves. Smart Materials and Structures, 19(1), 015004. doi: 10.1088/0964-1726/19/1/015004.

37. Ahmad, Z. A. B., Vivar-Perez, J. M., \& Gabbert, U. (2013). Semi-analytical finite element method for modeling of Lamb wave propagation. CEAS Aeronautical Journal, 4(1), 21-33. doi: 10.1007/s13272-012-0056-6.

38. Hayward, G., \& Hyslop, J. (2006). Determination of Lamb wave dispersion data in lossy anisotropic plates using time domain finite element analysis. Part I: theory and experimental verification. IEEE Transactions on Ultrasonics, Ferroelectrics, and Frequency Control, 53(2), 443-448. doi: 10.1109/TUFFC.2006.1593383.

39. Ramadas, C., Balasubramaniam, K., Joshi, M., \& Krishnamurthy, C. V. (2009). Interaction of the primary anti-symmetric Lamb mode $\left(\mathrm{A}_{\mathrm{o}}\right)$ with symmetric delaminations: numerical and experimental studies. Smart Materials and Structures, 18(8), 085011. doi: 10.1088/0964-1726/18/8/085011.

40. Srivastava, A., \& di Scalea, F. L. (2009). On the existence of antisymmetric or symmetric Lamb waves at nonlinear higher harmonics. Journal of Sound and Vibration, 323(3-5), 932-943. doi: 10.1016/j.jsv.2009.01.027.

41. Wu, X. H., Shen, Y. P., \& Sun, Q. (2007). Lamb wave propagation in magnetoelectroelastic plates. Applied Acoustics, 68(10), 1224-1240. doi: 10.1016/j.apacoust.2006.07.013.

42. Tua, P. S., Quek, S. T., \& Wang, Q. (2005). Detection of cracks in cylindrical pipes and plates using piezo-actuated Lamb waves. Smart Materials and Structures, 14(6), 13251342. doi: 10.1088/0964-1726/14/6/025. 
43. Lee, J. K., \& Kim, Y. Y. (2016). Tuned double-coil EMATs for omnidirectional symmetric mode Lamb wave generation. NDT \& E International, 83, 38-47. doi: 10.1016/ j.ndteint.2016.06.001.

44. Sun, W., Liu, G., Xia, H., \& Xia, Z. (2018). A modified design of the omnidirectional EMAT for antisymmetric Lamb wave generation. Sensors and Actuators A: Physical, 282, 251-258. doi: 10.1016/j.sna.2018.07.030.

45. Cheng, J. C., \& Zhang, S. Y. (1999). Quantitative theory for laser-generated Lamb waves in orthotropic thin plates. Applied Physics Letters, 74(14), 2087-2089. doi: 10.1063/1.123766.

46. Nakano, H., \& Nagai, S. (1991). Laser generation of antisymmetric Lamb waves in thin plates. Ultrasonics, 29(3), 230-234. doi: 10.1016/0041-624X(91)90061-C.

47. Kazys, R. J., Vilpisauskas, A., \& Sestoke, J. (2018). Application of air-coupled ultrasonic arrays for excitation of a slow antisymmetric Lamb wave. Sensors, 18(8), 2636. doi: $10.3390 / \mathrm{s} 18082636$.

48. Fan, Z., Jiang, W., \& Wright, W. M. (2018). Non-contact ultrasonic gas flow metering using air-coupled leaky Lamb waves. Ultrasonics, 89, 74-83. doi: 10.1016/ j.ultras.2018.04.008.

49. Myshkin Yu. V., Murav'eva O. V., Sannikova Yu. O., \& Chukhlanceva T. S. (2018) The propagation of horizontally polarized shear wave in the hollow cylinder. In Instrumentation Engineering, Electronics and Telecommunications - 2018: Proceedings of the IV International Forum: 12-14 Dec. 2018 (pp. 51-65). Izhevsk, Russia : Publ. House of Kalashnikov ISTU. doi: 10.22213/2658-3658-2018-51-65.

50. Myshkin, Y. V., Murav'eva, O. V., Fotina, A. A., \& Chukhlanceva, T. S. (2019). The propagation of symmetric Lamb wave in the hollow cylinder. In Instrumentation Engineering, Electronics and Telecommunications - 2019: Proceedings of the V International Forum 20-22 Nov. 2019 (pp. 85-97). Izhevsk, Russia : Publ. House of Kalashnikov ISTU. doi: 10.22213/2658-3658-2019-85-97.

51. Myshkin, Y. V., Muravieva, O. V., Voronchikhin, S. Y., Samokrutov, A. A., \& Shevaldykin, V. G. (2019). Geometric anisotropy of velocity of horizontally polarized shear wave in pipe. Journal of Physics: Conference Series, 1327(1), 012023. doi: 10.1088/1742-6596/1327/1/012023. 